\title{
Steering the future of travel demand: An interview with Greg Marsden about building dialogues and changing practices
}

\author{
By Allison Hui ${ }^{\mathrm{a}}$ and Greg Marsden ${ }^{\mathrm{b}}$ \\ a Department of Sociology, Lancaster University, UK \\ ${ }^{b}$ Institute for Transport Studies, Leeds University, UK
}

The Version of Record of this manuscript has been published and is available in Applied Mobilities http://www.tandfonline.com/10.1080/23800127.2020.1764239.

With governments around the world committed to radically reducing greenhouse gas emissions by 2050, and transport-related mobilities making up a significant proportion of current carbon emissions, questions of how to change mobility systems have become a pressing concern. Yet the urgency of this challenge cannot be met with more of the same particularly in terms of narrow discussions of behaviour change that fail to draw upon the wealth of relevant social scientific research (Shove, 2010). New methods of collaborating and bringing together communities - whether policymakers, academics, or publics - will also be key.

Greg Marsden brings a particularly interesting set of perspectives to the question of what future travel demand might look like, and how we can change practices to get there. While currently a Professor of Transport Governance at Leeds University, Greg has spent significant periods working with policymakers - both within Transport for London and supporting the UK Parliament Transport Select Committee, which scrutinises the UK Department for Transport's (DfT) spending and policies. Our conversation looks at how spaces can be fostered for new ways of thinking, communicating and collaborating to address the challenge of rapidly decarbonising transport systems. Though largely focused upon the UK, the conversation highlights issues related to policy engagement, theory and evidence, and understandings of sharing that will have much wider relevance.

AH: How has your varied career shaped the way you approach the challenge of building a sustainable transport system?

GM: My formal training is as a civil engineer, and my PhD was working in road traffic pollution estimation which was based on a formalised estimation of how traffic moves around a network and questions about how new technologies might work. But I spent a year working in Santiago, Chile, where they had a massive pollution problem. And there they did things which no traffic modeller in the world would have told you would work. Yet the system didn't grind to a halt. So I got really interested in the social dimensions of that the social acceptance that wouldn't have been imaginable in the UK but, because of the nature of the severity of the problem and maybe the type of government that they had, seemed to be acceptable. From then on, I was drawn in to trying to understand how policies get designed and implemented. It's nice to understand various sorts of evidence that get brought forward to make that possible as well, so I have kind of straddled the engineering and social science evidence base. And that has led me into all kinds of different things. 
$\mathrm{AH}$ : One of your recent projects is the Commission on Travel Demand, which you have described as a "meeting house for ideas and evidence" (Marsden, 2019). It draws upon a format where a call for evidence is published, a wide range of organisations respond in writing, and then some are invited to present evidence before a group of commissioners who write a final report. This kind of format is well established and has, for example, been used by the Transport Select Committee. But the Commission on Travel Demand was something you decided to establish yourself, whilst working in the DEMAND Research Centrei. How did you come to feel this kind of meeting house was needed?

GM: I've always found that there has been a bit of a gap between what academics do and talk about and what goes on in policy. It's not to say that academic evidence isn't used, but it's generally used more when it suits the purposes of the organisation. Knowledge isn't free of values in that sense. But that means that it is quite hard to change the nature of the debate about travel demand.

I felt quite passionately after the first half of the DEMAND Centre that there were some really important new insights that could and should be unlocking a different discussion about the future of travel demand. Yet I hadn't been able to make headway on that. I had tried in the Disruption Project where we did a lot of work with policy stakeholders. We prepared a new policy manifesto and it was well received, but ultimately it didn't go anywhere. There was no ownership of it. So what I wanted to do through the Commission was to bring policymakers together with academics to co-create shared outcomes which, once they become accepted, become part of something around which policy can be built. Given my experience on the Transport Select Committee, I felt establishing the Commission was a way of doing it. It not only allows exchanges with various people, testing of propositions and evidence that people had put forward, but also coming to conclusions that are based on evidence from not only academics, but also policy and industry.

$\mathrm{AH}$ : What has been most surprising to you thus far about engaging in this process?

GM: I don't think anyone has said no to coming along to a workshop and presenting evidence. It's hard work do a workshop every six weeks, which has been our schedule for the two inquiries that we have had. But it seems to have built a credibility and filled a hole that practitioners and policymakers and academics all identified with. I'm surprised it has been as successful as it has in providing that kind of meeting house environment.

$\mathrm{AH}$ : At the end of the Commission's first report, 'All change: the future of travel demand and the implications for policy and planning', you and the other commissioners write "This work is the continuation of a debate. We hope it is the start of a sea-change in practice" (Marsden, Dales, Jones, Seagriff, \& Spurling, 2018, p. 6). I think that aligns very well with one of the concerns of Applied Mobilities, which is looking at how intervention works in practice. To what extent do you think the Commission itself could be considered as a kind of intervention in practice?

GM: I probably conceived of it in that way without necessarily formally thinking about that. It was a different way of trying to have an engagement with policy and practice but one 
which allows them to meet halfway. That is one of the interesting things about it. As you know, individual behaviour change is the only lens through which much evidence in the UK Government and civil service is being considered. So when some new evidence comes up that doesn't really fit with that, the response is often 'how can we make it fit with that?' rather than 'have we found something new here?' So what was really good was that we were able to engage with some really fantastic resources that the Department for Transport had created, but which I don't think it really knew what to do with. So that - as an intervention in practice - was surprising. They had already challenged their own practice in some ways, but the next steps with the evidence they had were not clear.

$\mathrm{AH}$ : The first inquiry on the Future of Travel Demand presented quite striking evidence of how much travel demand is already changing in terms of generational change, young people learning to drive later and travelling less, as well as change in travel related to things like food delivery and next day delivery. These trends are highlighting we are not at all in the same circumstance that we were previously. What evidence did you find particularly striking from the first inquiry?

GM: The UK Government's own statistics show that overall levels of travel per head of population have been falling for more than 15 years. But that evidence had not yet made any difference to their thinking about what the future of travel demand will be. Instead, there is always an assumption that we will want to travel further as we get wealthier. Another interesting part of their work relates to commuting patterns. Despite the fact we've never had more people in work, there are fewer commute trips going on. So the whole nature of work is changing, yet I think we still plan for transport to be a 9 to 5 , five day a week kind of opportunity. So all of our incentives, season tickets and everything, are designed around that pattern which, for large parts of the population, like those working part time or in the gig economy, is not how it works. Even the premise that peaks in morning and evening travel are in some way a stable phenomenon that we need to be tackling is being challenged. Yet so much of our transport planning remains based around sorting out problems with the commute.

$\mathrm{AH}$ : The recommendations from first inquiry try to make a leap from evidence such as that to thinking about what it means for particular government departments. What do you think is one of the most important recommendations of that report?

GM: I think the most important one is related to the limited attention to different possible futures. The Committee on Climate Change (CCC) isn't allowed to develop its own estimations of what future demand could be. It's allowed to assess Government's progress towards carbon reduction commitments. So essentially it's working to the middle growth forecast for future travel demand. That means that it is already hard-wired into its future assessment of progress towards carbon reduction that there isn't going to be a significant demand change. And therefore everything else has to be a technological solution. The only way you can address this limitation is if the DfT starts to think about what reasonable, possible, plausible demand futures are going to be.

I never appreciated until we got through the inquiry, why the CCC looked at it in the way that it did. But it looks at it because that is the way that the DfT looks at it. And to some degree the DfT looks at it the way that it does because the Treasury says 'These are your 
growth forecasts' and unless they are able to re-think how that will play out through society, we're stuck in the same paradigm we have been in for forty years.

AH: I'd be interested to hear you say a little bit more about how you approach the relationship between evidence and theory. Certainly a lot of social scientists are trained to recognise that the kinds of conceptual tools you are using, and the way you are approaching particular problems, shapes what kinds of evidence are important, indeed what the evidence is. In terms of engagement though, there is always the challenge that making theory too present - especially when it involves unfamiliar concepts - can make it more difficult to highlight the relevance of new approaches for non-academic practice. In the Commission, how have you approached the aim of fostering new ways of thinking about evidence, when this is informed by different kinds of theoretical approaches?

GM: I lean quite heavily on co-commissioner Nicola Spurling for thinking about how best to do that through the two inquiries we have done to date. So one way of doing it is, for example with social practice theory, to try and think about which of the terms we use in everyday policy practice already connect to theories of social practice and how we can make the evidence that is already there talk better to a new framing of thinking about demand change. So not to try and have that discussion in new terms that won't mean anything to anyone, but to do your best to reengineer the vocabulary that is already out there in different ways. With our sharing inquiry, there is quite a lot of negative response in UK policy to the idea that we should ask people to share more. But instead of asking individual people to share more, such as giving up the car for a few days, it could be framed as creating new systems where sharing becomes more normal. We could be asking people to do more of the sharing they already sometimes do, rather than to try to do something different. So our approach is to have the conversation in terms of more or less of the normality of sharing rather than creating sharing as some new box which is an intervention that we have to create something new around. What is it about current ways of sharing that is important to, for example, embed trust in sharing and therefore to grow it.

So we try to approach changing ways of thinking through existing tools and language, more than anything. It's kind of bringing theory in through the back door slightly, but I guess we've always tried to have that theoretically-inspired way of trying to organise the conversation. You know, recognising that things like practice theory are really good at describing things but not necessarily easy to interpret for policy makers as a model of change.

$\mathrm{AH}$ : So being able to describe evidence people are already somewhat familiar with in a very different way is already potentially a step towards imagining different practices and processes.

GM: Yes - one example from the first commission was Lynn Basford who is involved in planning applications for housing, who has picked up the report, and started to build upon it. One of the things we do in housing developments is we look at previous housing developments and how many car-based trips they have generated and they use that as a basis for projecting forwards. She has challenged this because she has a developer who wants to do something quite different. Although the tools we would normally use tell us we should be planning for more car-based trips, the evidence is that we ought to be planning 
for less. We have done some follow-up work and looked at the data on car travel plans for housing, and it's declining over time. But normally planers would not have looked at that. They have always just assumed that the ten year average is constant. But it's actually declining as a trend. So she doesn't care about practice theory, but she has bought into the idea that a different travel future could be created by some of the places that are built.

$\mathrm{AH}$ : So you mentioned already the second inquiry, which you are in the middle of at the moment, on shared mobility. I was quite intrigued by some of the ways that waste has been described in relation to existing patterns of car mobility and the 621 billion empty vehicle seat miles that were driven in the UK last year. There is a lot already being discussed about sharing, so what do you think the commission is starting to unearth in terms of new perspectives on how we think about sharing as possibly a new model for different types of businesses and mobilities?

GM: If net zero is taken seriously, then we have to find some way of accelerating decarbonisation. And libertarian governments struggle with restriction as a means of doing that. So sharing in some sense is going back to a very social way of travelling. We used to share more than we currently do, quite considerably. There are other places in the world that have similar levels of GDP that share more than we do. So these conditions can be created. But I guess the majority of people who are working in local government and councils and so on are not necessarily looking to promote these kinds of opportunities. So we are trying to say 'Where could you make sharing more socially acceptable?' 'Where could it fulfil a role that is not just about carbon saving but is about creating a more social way of moving around, dealing with some of the issues: costs of motoring, rural isolation?' There are all sorts of things that sharing can do beyond carbon reduction, if we think about the broader meanings of sharing. You've got to go beyond our existing economic framing of mobility in order to unlock new thinking about how to do this, and what sorts of resources are necessary to make it happen. Governments are prepared to fund capital investment in roundabouts and such but not social investments in mobility. So part of the challenge is trying to make them aware that some sharing schemes that are successful aren't financial viable, but have much wider social benefits in terms of the whole of government and what they are trying to achieve. So we are trying to broaden the nature of the debate, the reasons why sharing might be considered and the histories and possible futures that could be created if we took it seriously.

$\mathrm{AH}$ : That is interesting because there was another interview in this journal with Soren Riis, the co-founder of GoMore, a ride- and car-sharing company in Denmark. He was talking in that interview about how in Denmark there has been more political willingness to support sharing economies but there is still a lack of insight in that people think this is something that will help but then get distracted with debates about Uber, for example, which has been received very poorly. To what extent do you think that there are important international similarities or differences when it comes to addressing this issue of shared mobilities and the future of policy mobilities?

GM: I think cross-national comparisons are really interesting because it shows you, for example in cultures that you can relate to, that things are already working differently. And sometimes in places where perhaps you can't quite imagine yourself, you can see systems in 
operation that are actually quite amazing and innovative. This really shows that how society organises itself isn't a given and we can think about re-shaping it. I do a bit of work in India and I'm amazed to see the amount of sharing that goes on there within the really busy, crowded centres. But, when it comes policy discussions, I find it maybe opens an opportunity for a discussion but it doesn't tend to get much further than that. You get down into the, 'Yeah, well, Scandanavians are different because such and such.' In a sense we have probably got a massive amount of diversity in shared mobility in the UK if we really went looking for it. Maybe it would be more effective to find those examples of diversity in the UK and what they are really delivering and how they really work. It might be more persuasive in policy terms.

$\mathrm{AH}$ : And I can imagine thinking about, for example, local government versus national government and the different ways that they have supported sharing as a means of gathering communities or addressing quite different concerns. I can see that there would be considerable variation there as well.

GM: The thing that has probably disappointed me most is that Highways England do not have a direct responsibility for thinking about the car occupancy on the motorway network and so they think about the need for new capacity very narrowly. There are a huge amount of miles that are driven in the UK but they do things like close off informal parking areas around junctions where people meet up and do ride share, because of safety reasons. Rather than seeing that as an opportunity where there are some people who want to share, and we could provide for them, it gets closed off. So there isn't a connective mindset at these different spatial scales. The national government never set a requirement for Highways England to think about that as part of their regulatory rules. So therefore they are not going to do it because they aren't judged against that and if they did do stuff around it, it's possible they could even be challenged on it at the moment. Yet instead of widening a motorway lane and spending however many million pounds per mile, if you've got more people sharing, you wouldn't need the physical capacity but you would have the capacity through the journeys that are already being made, so it's kind of a mindset thing. Scale does matter because at a national level, there might be questions about 'who are we as national government to tell people about what kind of sharing they should do?' But it does matter in the way that they decide what kind of funding to provide and how they are assessing parts of their network.

AH: I'm curious about how you see the Commission as fitting into this moment in history where we have Fridays for Future and government declarations of a climate emergency. You've recently retweeted a newspaper article by Dr. Steve Melia entitled 'How I went from government adviser to convicted climate protester' (Melia, 2019) that raises important questions about whether established methods of academic engagement are ever going to be enough to address the climate emergency. Prof. Jillian Anable has also pressed this point further in her keynote at the Universities' Transport Study Group Conference (Anable, 2019). How do you respond to such reflections upon how academics address the gap between academic and policy spheres?

GM: We need all sorts of different types of academic interventions. I think in order to enable government to take a different position we've got to explain to them that a different 
position is possible without the sky falling in. I know that those engaged with discussions of the climate emergency would argue that we haven't got time for government to come to a dawning realisation on this. Maybe we will have some crisis politics. But we've had crisis politics in the past and it hasn't really changed the way we think about mobility and how it might change. So I've taken the view that I have got to push as hard as I can on the various different forms of intervention and try and take the Department for Transport along. And it may be that it needs a different political leadership or a different point in political time for this to suddenly open up and become a possibility. But I guess I've kind of seen my work or responsibility not as necessarily being at the more radical end of demonstrations or so on, but in trying to create an environment in which the government can do something different in response to that.

$\mathrm{AH}$ : And finally, what has most inspired you in your time working on the Commission?

GM: I guess the biggest buzz I have had is that the Department for Transport actually responded to the Commission's report. It didn't have to formally respond - the Commission doesn't have any status in that sense. But it appears to have found quite a space in policy and practice at this point in time so it's something that people have been listening to, engaging with and recognising as having potential to change practice. Given previous experience where it was very difficult to get different organisations to engage, maybe this is evidence that it just takes time and it takes particular ways of working, which are probably different in different sectors. But you can foster that community for changing things.

References

Anable, J. (2019). Rearranging elephants on the Titanic: the astonishing absence of the carbon reduction imperative in transport policy and research. Paper presented the Universities' Transport Study Group Conference, Leeds.

https://www.creds.ac.uk/rearranging-elephants-on-the-titanic-jillian-anableskeynote-presentation-from-utsg-annual-conference/

Marsden, G. (2019, 15 March 2019). All change? DfT responds to Commission on Travel Demand Report [Blog]. Retrieved from

https://drgregmarsden.wordpress.com/2019/03/15/all-change-dft-responds-tocommission-on-travel-demand-report/

Marsden, G., Dales, J., Jones, P., Seagriff, E., \& Spurling, N. (2018). All change: the future of travel demand and the implications for policy and planning. Retrieved from

http://www.demand.ac.uk/wpcontent/uploads/2018/04/FutureTravel report final.pdf

Melia, S. (2019, 7 August 2019). How I went from government adviser to convicted climate protester. The Guardian online. Retrieved from

https://www.theguardian.com/commentisfree/2019/aug/07/climate-changeextinction-rebellion-london-protest-arrested

Shove, E. (2010). Beyond the ABC: climate change policy and theories of social change. Environment and Planning A, 42, 1273-1285.

\footnotetext{
i www.demand.ac.uk
} 